\title{
Spatiotemporal Variations in \\ Heat-Related Health Risk in Three Midwestern U.S. Cities Between 1990 and 2010
}
Daniel P. Johnson Ph.D., J. Jeremy Webber M.S., Kavya Urs Beerval Ravichandra M.S., Vijay Lulla Ph.D., and Austin C. Stanforth M.S.
Department of Geography, Indiana University Purdue University, Indianapolis, U.S.A.

\author{
Daniel P. Johnson Ph.D.* \\ Assistant Professor \\ Indiana University, Indianapolis, Geography \\ 425 University Blvd. CA 209c \\ Indianapolis, IN, USA 46202 \\ dpjohnso@iupui.edu \\ 317-278-5536 \\ J. Jeremy Webber M.S. (jwebber@iupui.edu) \\ Kavya Urs Beerval Ravichandra M.S. (kavbeerv@iupui.edu) \\ Vijay Lulla Ph.D. (vlulla@iupui.edu) \\ Austin C. Stanforth M.S. (austin.stanforth@,gmail.com) \\ *This is an Accepted Manuscript of an article published by Taylor \& Francis Group in Geocarto \\ International on $12 \mathrm{Jul}$ 2013, available online at: http://dx.doi.org/10.1080/10106049.2013.799718
}




\begin{abstract}
Mortality from extreme heat is a leading cause of weather-related fatality, which is expected to increase in frequency with future climate scenarios. This study examines the spatiotemporal variations in heat-related health risk in three Midwestern cities in the United States between the years 1990 to 2010; cities include Chicago, Illinois, Indianapolis, IN, and Dayton, OH. In order to examine these variations we utilize the recently developed Extreme Heat Vulnerability Index (EHVI) that uses a principal components solution to vulnerability. The EHVI incorporates data from the U.S. Decadal Census and remotely sensed variables to determine heat-related vulnerability at an intra-urban level (census block group). The results demonstrate significant spatiotemporal variations in heat-health risk within the cities involved.
\end{abstract}

Keywords: extreme heat; weather-related fatality; climate; heat-related health risk; remote sensing

\title{
Introduction
}

The scientific community is concerned over the growing threat from changes to Earth's climate (Bird., Dorworth., \& McCormick., 2010; Horton et al., 2010). Independent of the current debate regarding anthropogenic forces on Earth's climate, heat waves have consistently been ubiquitous across the globe and within many distinct climates. Heat waves are not the only climate-related disasters that have been present in Earth's climate signal; flooding, drought, extreme precipitation events, and cold waves are just a sampling of other disasters which appear to be increasing in duration and frequency. However, heat waves are considered to be the phenomena most exacerbated by recent climate change (Jackson \& Shields, 2008; Patz et al., 2000). Therefore, the expectation is that heat-related health impacts will become more widespread and more common within a changing climate scenario. Regardless of the sensitivity and specificity of climate models, humans and agencies tasked with mitigating extreme heat disasters will undoubtedly need more information in which to drive decision processes.

There has been a recent surge in research activity attempting to define vulnerability as it relates to climate risks. Much of this research deals with extreme heat events, working to 
identify numerous factors which are most indicative of extreme heat health risks. Aged populations, those with lower educational attainment, minority racial populations, and the economically disadvantaged are socio-demographic categories which appear to be predominantly indicative of extreme heat health risk (Browning, Wallace, Feinberg, \& Cagney, 2006; Harlan, Brazel, Prashad, Stefanov, \& Larsen, 2006; Uejio et al., 2011). Additionally, there are environmental components to extreme heat health risk which can be effectively monitored with space-based satellite platforms. The normalized difference vegetation index (NDVI) provides clues to the amount of photosynthetically active vegetation, the normalized difference built-up index (NDBI) provides utility for delineating urban built areas, and land surface temperature (LST) provides details concerning the environmental temperature (Jensen, 2005; D. P. Johnson \& Wilson, 2009; D. Johnson, Wilson, \& Luber, 2009). Harlan et al. (2013) documented how vegetation could act as a protective variable (Harlan., Declet-Barreto., Stefanov., \& Petitti., 2013). These socio-demographic and environmental variables have been combined into a Extreme Heat Vulnerability Index (EHVI), and have been tested in the context of the 1995 Chicago heat wave (D. P. Johnson, Stanforth, Lulla, \& Luber, 2012) and a NASA ROSES grant project involving multiple cities. Documentation and results from the NASA ROSES project have not yet been made public, as the study is on going, but preliminarily results match those demonstrated from the Chicago analysis previously mentioned.

One important aspect which is missing from studies on extreme heat in a spatial context is the addition of the temporal dimension. Numerous studies have shown the temporal nature of mortality during heat waves, but little has been done for systemic studies across regions (Reid. et al., 2012). In the present research we plan to compare the EHVI methods of identifying heatrelated health vulnerability through time in three Midwestern U.S. cities - Chicago, IL, 
Indianapolis, IN, and Dayton, OH- from 1990 to 2010. This will be accomplished using NASA satellite imagery and census data from 1990, 2000, and 2010. Such a spatio-temporal analysis will provide further guidance on vulnerability within these locations and demonstrate how vulnerability prevention plans require renewal for improved accuracy over time to compensate for population migration and changing physical environments.

\section{Background}

Heat is currently considered one of the primary causes of weather-related mortality in the United States, most specifically when it is accented by heat waves or extreme heat events (Luber \& McGeehin, 2008; Wilhelmi \& Hayden, 2010). Heat is considered to be such a viable threat because it does not produce visual signs of inclement weather danger, such as high winds or storm clouds, and because it has a multitude of negative impacts on the human body. Heat exacerbates pre-existing medical conditions, such as cardiovascular complications, renal conditions, mental illness, diabetes, and other thermoregulation complications (Hondula. et al., 2012). Prior studies have demonstrated populations age 65 and older consisted of up to 70 per cent of the heat-related fatalities during the 1995 heat wave in Chicago, IL. Heat waves can also cause increased mortality amongst healthy individuals through dehydration and heat stroke, so the threat to vulnerable or at risk populations is greatly exacerbated by extreme heat (Changnon., Kunkel., \& Reinke., 1996). Therefore, socio-vulnerability indicating variables should be incorporated into more sophisticated warnings, which could prove beneficial to individual survivability during inclement heat weather.

The 'original' heat warning system in use by the National Weather Service utilizes meteorological measurements to identify oppressive weather events, but do not incorporate 
environmental or vulnerable attributes. One system currently implemented is the Heat Health Watch Warning System (HHWWS), which focuses on atmospheric conditions which have previously associated with heat-related mortality (Kalkstein, 1991; Kalkstein, Jamason, Greene, Libby, \& Robinson, 1996). The HHWWS's limitations include a lack of spatial specificity, lack of vulnerable population consideration when determining risk and it focuses on larger spatial entities, such as city or county boundaries (Harlan et al., 2006; D. Johnson et al., 2009).

Determining variations in vulnerability between localized areas is a developing functionality that should significantly contribute to future mitigation of heat-related health concerns (Harlan et al., 2006; Kalkstein, 1991; Kalkstein \& Greene, 1997; Kalkstein et al., 1996; Wilhelmi \& Hayden, 2010).

Other heat vulnerability studies identify populations who were at higher risk by socioeconomic variables only. Many sociologists are familiar with the 'SoVI' or the social vulnerability index pioneered by Cutter and associates (Cutter, Burton, \& Emrich, 2010). This approach utilizes numerous demographic variables to determine the level of social vulnerability for each county in the conterminous United States. The SoVI is not specific to any particular natural phenomena or location, but rather is a global measure of vulnerability generalized to a variety of natural or societal hazards. Furthermore, it maintains a larger spatial zone by utilizing county boundaries, even though it is applicable at a finer level of aggregation. The SoVI does not incorporate physical attributes to its vulnerability index (Cutter et al., 2010).

To consider how both social and environmental aspects of health risks correlate with extreme heat exposure requires the development of heat systems specific to vulnerability indexes and related to spatial variables. One of the earlier known attempts was Harlan et al.'s (2006) 
Human Thermal Comfort Index (HTCI). This index was designed to incorporate spatial relationships to environmental stress, thermal variations, and vulnerable populations.

Extrapolating these ideas led to the creation of the previously mentioned EHVI, which further utilizes social and environmental aspects of health vulnerability to extreme heat. Reid's study did suggest local scale testing was a more optimal approach eluding that regional-scale analysis cannot account for minute discrepancies in vulnerable or physical attributes, as the EHVI procedures entail (Reid. et al., 2012). The EHVI utilizes remote sensor platforms to focus within urban features to incorporate temperature and other environmental factors, such as the NDVI and NDBI, across micro-environments to improve spatial specificity of the analysis and warnings beyond currently available systems (Dan Johnson, 2011). Specific spatial warnings should improve warning utilization by civilians through decreased message fatigue (Shen, Howe, Alo, \& Moolenaar, 1998). These improvements also allow for enhanced disaster mitigation practices which focus preventative aid and assistance to areas at an increased risk (Hondula. et al., 2012). If properly implemented, these techniques could save lives and reduce costs, through fiscally efficient mitigation plans and decreased hospitalization costs. Improved prevention plans could guide the optimal placement and utilization of new cooling and community aid centres, so fewer would need to be built, and could even be used as documentation when applying for disaster prevention funding.

In order to develop extreme heat vulnerability models that utilize satellite imagery, it is important to consider several relationships between the data and the local environment (Hondula. et al., 2012; D. P. Johnson et al., 2012). During a heat wave, the intensity of the surface urban heat island can be disproportionally distributed across an urban landscape. The following 
visualization was developed by utilizing 16 cloud free Landsat 5 images from the year 2011 and calculating the percentile ranks for each pixel (Unites States Geological Survey, 2009). These are displayed as either: below the $90^{\text {th }}, 90^{\text {th }}, 95^{\text {th }}$, and $97^{\text {th }}$ percentile of LST, a similar procedure utilized by weather services to designate periods of heat wave intensity. Composite images, such as the following figure, were utilized for this analysis to reduce the impact of cloud or aerosol confounding errors when identifying areas of normally higher LST measurements. Even though the EHVI focuses on heat waves, it is believed that an association between extreme and normal temperature health impacts exists within discrete areas and therefore imagery acquired on non heat wave days can still identify areas of increased heat impact (Reid. et al., 2012). This methodology is currently being developed and is not included in the spatial and temporal analysis of this study.

Figure 1. Landsat 5 Thermal Imagery Percentiles, Philadelphia 2011.

[Figure 1 near here]

\section{Methods}

This study was conducted as an experiment in whether the EHVI's ability to identify vulnerability changes across both space and time. This article and the methods demonstrated here is not an attempt at justification for the EHVI, rather to understand the implementation of mitigation plans over time. Therefore, although a brief outline of EHVI methodologies will be presented for background information, the main methods involved for this article reflect the procedure of spatial and temporal analysis utilizing the EHVI functions. For a more precise description of the methodologies behind the EHVI, Johnson et al. (D. P. Johnson et al.) should be consulted. 


\section{Demographic and Socioeconomic Data}

For EHVI analysis, raw demographic and socioeconomic data was collected at the block group level for the years of 1990, 2000, and 2010. Data was obtained through the U. S. Census FTP web based portal at www2.census.gov. The 1990 Census of Population and Housing Summary File 1 and Summary File 3 contain the necessary data to tabulate general demographic and socioeconomic information, such as total population, race, age, sex, educational attainment, income, poverty status, and age of householder. The consistencies of these variables were closely maintained in the 2000 Summary Files 1 and 3 with only a few differences noted in the variables collected from the previous decennial census. In 2000, educational attainment was subdivided by sex giving a total of two additional variables; total male and total female with no high school degree.

The U.S. Census restructured their collection methods for several variables in the 2010 dataset. The 2010 Summary File 1 maintains continuity with the basic demographic counts, however the data previously recorded in Summary File 3 for 1990 and 2000 had been replaced in 2010 with estimations obtained by the American Community Survey (ACS). In previous decennial censuses, sample data are weighted to represent the total population, whereas the ACS data are based on one, three, and five years estimations. In order to match as many variables from 2010 to previous decades, this study used ACS five-year estimations (2006-2010) at the block group level. One and three year estimations either lacked the necessary variables or were not tabulated at the correct enumeration unit for this study.

Air conditioning prevalence can be extrapolated from the census data, however it is only a survey variable rather than count and it does not demonstrate utilization. Harlan et al.'s (2012) 
used an air conditioning variable in their desert study as use of the devises is high; incorporation of such a variable within the Midwest, however, cannot be quantified so easily. If a household has an air conditioning system, it does not demonstrate their financial ability to use it, so such a variable has not been included for this study, nor for the EHVI. This is one aspect which sets the EHVI apart from other research projects, such as the HVI (Reid. et al., 2012) which only studied areas where air conditioning was present.

\section{Remote Sensor Data}

Satellite imagery from the Landsat $5 \mathrm{TM}$ instrument were collected for each of the cities. Individual cloud free scenes were selected during the summer months of each decade and converted to a LST. The thermal band was changed to LST following emissivity correction procedures outlined by (Dousset \& Gourmelon, 2003; Weng, Lu, \& Schubring, 2004). The residential space within each census boundary was identified from the National Land Cover Dataset from 2001 and 2006, the most recent applications at the time of this writing, according to the USGS website. The LST, NDVI, and NDBI pixels that spatially coincided with residential land use were then averaged and joined to the socioeconomic data, via ESRI Arcmap, to provide a metric for each within the residential areas.

The socio-demographic variables were also normalized by the amount of residential land area within each census tract. Therefore, the metric is a density measure based on the specific socio-demographic variables and total area of residential space; not the area of the census tract. This approach eliminates extraneous areas within the census tracts where there is no human settlement pattern, and reduces confounding errors which can be created by large industrial areas (Fry, 2011; Homer, 2007). 


\section{Analysis through Principal Component Analysis}

Analysis of the previously mentioned input variables were statistically analyzed through the utilization of a Principal Component Analysis (PCA) statistical modeller. The dependent variable utilized for the PCA was found through death certificates where heat was listed as a contributing factor. The dependent variable was acquired for a NASA ROSES, and is not present here due to Institutional Review Board (IRB) restrictions. The dependent variable was kept consistent for each study area through the three decades to accentuate the implementation of changes in environmental and socioeconomic changes. The environmental and sociodemographic variables were normalized to produce z-scores and used to create a principal components solution utilizing maximum variance between all incorporated variables. This approach was used to develop the EHVI, further outlined in Johnson et al. 2012. Parameters of the Principal Component Analysis (PCA) include varimax rotation and retention of components with eigenvalues in excess of 1 (Kaiser criteria). The components are then summed and joined to census identifiers to create a risk assessment map at the census boundaries. Categories are stratified into 6 groups based on z-scores of the EHVI. Values range from greater than $2 \mathrm{z}$, being the highest risk $(\mathrm{HH})$, to less than $-2 \mathrm{z}$ being the lowest risk (LL).

In addition to mapping the variables, we also calculated Moran's $I$ for each decade and each city to determine the changes in spatial clustering of vulnerability (Moran, 1950). Moran's $I$, as utilized in this study, is a global measure of spatial autocorrelation and determines levels of perfect autocorrelation, or clustering, and levels of perfect dispersion. Values for this index range from -1 , which is perfect dispersion, to +1 which is perfect spatial autocorrelation. Values 
near zero indicate a random process. We utilized a polygon continuity matrix to determine proximity of values and assume lower values to be more dispersed in their spatial arrangement than higher values.

\section{Results}

Tables $1-3$. EHVI Loadings by City

Table 1 (a). Chicago 1990 EHVI Loadings

[Table la near here]

Table 1 (b). Chicago 2000 EHVI Loadings

[Table $1 \mathrm{~b}$ near here]

Table 1 (c). Chicago 2010 EHVI Loadings

[Table 1c near here]

Table 2 (a). Indianapolis EHVI 1990 Loadings

[Table 2a near here]

Table 2 (b). Indianapolis EHVI 2000 Loadings

[Table $2 \mathrm{~b}$ near here]

Table 2 (c). Indianapolis EHVI 2010 Loadings

[Table 2c near here]

Table 3 (a). Dayton 1990 EHVI Loadings

[Table 3a near here]

Table 3 (b). Dayton 2000 EHVI Loadings

[Table 3b near here]

Table 3 (c). Dayton 2010 EHVI Loadings

[Table 3c near here] 


\section{Chicago EHVI}

Vulnerability factors related to the elderly population are weighted in the middle of the component matrix for 1990, whereas in 2000 and 2010 the aging population is weighted as being more vulnerable to extreme heat. Children age five and below are weighted as being more vulnerable in 1990. In 2000 and 2010 vulnerability factors related to youth are weighted in the middle of the component loadings. Hispanic populations are consistently weighted in the middle of the component matrix. In 2010 males age five and under are ranked as being more vulnerable than females age five and under. For 1990 and 2000 the Asian population was ranked as less vulnerable, while in 2010 the Asian population is now trending towards being more at risk to extreme heat.

\section{Indianapolis EHVI}

In 1990 the most vulnerable are the elderly and black populations. In 2000 vulnerability factors related to children age five and below, the total population, and those below poverty are ranked as being more vulnerable to extreme heat than the elderly and black populations. Also, those without a high school degree are weighted as being more vulnerable in 2000. In 2010 children age five and below still retain high component loadings with the addition of the Hispanic population becoming more vulnerable as well. Those without a high school education in 2010 tend to be ranked less vulnerable then from previous decades. In 2010 LST, NDBI, and NDVI are ranked higher than in previous decades. The elderly vulnerability factors and educational attainment values tend to factor less in the EHVI for 2010 then previous decades. 


\section{Dayton EHVI}

In 1990 and 2000 vulnerability factors related to the elderly populations are weighted higher in the component loadings then the year 2010. For the year 2010 vulnerability factors related to children age five and under are more strongly contributing to the EHVI then previous years. Based on this analysis, the Hispanic population is becoming more at risk to extreme heat than in previous years observed. In 1990 and 2000 Hispanic populations are weighted lower in the component matrices, whereas in 2010 the Hispanic population is weighted in the top five of the vulnerability factors. For 1990 and 2000 median household income is observed as being weighted higher in the component matrices. In 2010 median household income is weighted within the bottom five in the component loading matrix.

\section{Clustering of EHVI Values}

Table 4 shows Moran's I for each city during each decade analysis. Although, each value for I does indicate statistically significant clustering, comparing the values to the maps presented in Figure 2 provides some further clarification of the distribution of vulnerability to extreme heat. In Chicago, the maps of vulnerability for 1990 and for 2000 look different and the Moran's index calculates as 0.466 and 0.630 respectively. For 2010 Moran's provides a metric of 0.594 , which indicates a further dispersion of vulnerability than in 2000. In Indianapolis, the values for 1990 and 2000 change dramatically with Moran's I calculated as 0.412 and 0.271 respectively. This indicates tendency toward dispersal in the values for Indianapolis from 1990 to 2000. The value for 2010 becomes slightly more clustered with a presentation of 0.396 . In Dayton, the value begins as more dispersed at 0.443 in 1990, becomes slightly more clustered in 2000 at 0.480 , and becomes more dispersed again in 2010 with a value of 0.402 . 
Table 4. Moran's $I$ index for each of the cities during each decade examined.

[Table 4 near here]

\section{Discussion}

As previously mentioned, the number of variables factored into the principal components analysis varies through time due to changes in the U. S. Census data collection methods. This is a limitation and a primary reason why the EHVI would need to be updated through time because utilization of similar census variables would not be available. We attempted to use variables that were as close between study periods as possible (Reid. et al., 2012). For the year of 1990, 24 vulnerability factors are included in PCA analysis, in 2000 there are 26, and in 2010 there are 21 in each city. There are distinct patterns in the component loadings which can be observed across all cities in this study. Physical variables in the component loading matrix (LST, NDBI and NDVI) are weighted lower than many socio-economic variables, such as populations under five and over 65 years of age, but should not be disregarded due to their significance in the loading tables. This is particularly true when you consider the spatial resolution of the Landsat 5 sensor, which has larger spatial data recording than the utilized Census boundaries leading to a generalization. Improved spatial resolution available through other sensing systems could provide better identification of at risk areas. Asian, Black, Pacific Islander, and White populations show a pattern of being weighted lower in the PCA component matrices than other variables indicative of race. All of the previously mentioned variables vary in significance between decades, which demonstrates the necessity for improved and constantly updated models to account for the temporal changes. The results reinforce the idea that vulnerability to extreme heat changes spatiotemporally, based on changes in demographics and the physical environment. Had the vulnerability variables remained constant, and the location of vulnerability remained 
locked, it would suggest that vulnerability assessments only need to be conducted once. Rather the changing loading of vulnerability over time demonstrates vulnerable traits migrate throughout urban landscapes and need to be reassessed to identify populations of increased vulnerability. Similarly, since different loadings occurred between different cities, even within the same decade, it demonstrates how precise vulnerability assessment needs to be conducted at a very local level.

When using the EHVI to visualize the extreme heat vulnerability in each of the cities across each decade, some interesting patterns occur. It is apparent from this analysis that vulnerability to extreme heat is not static, and there is significant variability to the spatial and temporal patterns of vulnerability. For Chicago during this time period, the pattern of vulnerability tends to become slightly more clustered through the time periods; although less so than in 2000. The pattern observed in Indianapolis becomes more dispersed, opposite of Chicago. Dayton, similarly, tends to become more dispersed throughout the period. These patterns have much to do with community-level determinants of heat-related health risk and the socio-demographic characteristics of the census boundaries examined. The socio-demographic makeup of the census values changes from one decadal census to the other as migration from the central city is evident in the 20 years of the study. This is mostly due to urban sprawl in Indianapolis and Chicago with different patterns of sprawl; Dayton does not experience the degree of sprawl as the other cities. The urban heat island effect tends to follow the sprawl patterns of a city. The temporal pattern of LST within this examination changed similarly. In addition to LST, the satellite detected NDVI and NDBI, changes during the time period as witnessed in all the cities examined. 
The pattern of vulnerability changes within the loading matrices of the EHVI solutions as well. In Chicago the environmental (LST, NDVI, and NDBI) metrics account for $12.23 \%$ (16.07\% of total), $11.70 \%(15.48 \%$ of total $)$, and $13.67 \%(17.68 \%$ of total $)$ of the variance in vulnerability from 1990, 2000, and 2010 respectively. Environmental variables in Indianapolis accounted for $12.87 \%$ (17.06\% of total), $14.10 \%$ (18.45\% of total), and $16.30 \%(20.40 \%$ of total) of variance in 1990, 2000, and 2010 respectively. In Dayton, the same variables accounted for $12.35 \%(16.06 \%$ of total $), 11.91 \%$ ( $15.05 \%$ of total $)$, and $14.99 \%(19.88 \%$ of total $)$ of the variance similarly. The percentage of variance as a total (in parentheses) consistently ranges around $16 \%-17 \%$ for the satellite-detected variables. This accounts for a significant portion of the observed vulnerability and is further validation for the inclusion of satellite-based metrics in vulnerability analyses.

There are implications for mitigation planning and response strategies for extreme heat events when there are significant variations in vulnerability observed over time. As indicated by Stone, sprawling cities seem to be more prone to heat-related health issues than cities that display less sprawl (Stone., Hess., \& Frumkin., 2010). As is known, urban sprawl places increased strain on vital resources provided by city utilities and emergency services. Furthermore, in the context of extreme heat events, a sprawling city is more likely to be a difficult city in which to plan mitigation and response strategies due to the migration of vulnerable populations and the spatiotemporal changes in the physical structure and environment. This study alludes to the difficulty in identifying vulnerable population locations over time without consistent documentation, especially under an urban sprawl regime. Although our study indicates varying levels of spatial dependence of vulnerability, the trend tends to become more dispersed through time, especially in the case of Indianapolis, IN. It would be less strenuous for emergency 
planners to plan heat response plans if the vulnerable populations were clustered centrally in one intra-urban location and not dispersed in disparate communities; thereby delivering valuable resources to an overall smaller geographical area. However, in the three cities analyzed this is not apparent and the locations of vulnerable populations tend to be significantly variable through time, apart from a few static locations (Figures 2 - 4).

The analysis in this study further demonstrates how diverse local-scale variations in vulnerability are within each location. As shown from the loading matrices, the weights of vulnerability are significantly different through time, but are perhaps even more different between the cities themselves. For example, if we were to utilize the PCA output from Chicago in 1990 to assess risk for Indianapolis in 1990, there would be a drastic misidentification of risk. Rather, creating an assessment for each city demonstrated the unique interplay between variables of risk distinct between cities. This is an important finding, because it demonstrates how inefficient previously utilized regional warning systems are, and how necessity local analysis is. Just as the temperature threshold warranting an extreme heat warning in Chicago is different from that of Indianapolis or Dayton due to variations in regional climate models, the unique mix of social and environmental variables create different assessments of vulnerability for each location. This also indicates it may be unlikely that a universal extreme heat vulnerability model could be developed for a large regional or national study.

Figure 2. Chicago EHVI 1990, 2000, and 2010 Map

[Figure 2 near here]

Figure 3. Indianapolis EHVI 1990, 2000, and 2010 Map

[Figure 3] near here]

Figure 4. Dayton EHVI 1990, 2000, and 2010 Map 
[Figure 4 near here]

\section{Conclusions}

This study demonstrates the unique spatiotemporal variability of extreme heat vulnerability in the cities of Chicago, Illinois, Indianapolis, Indiana, and Dayton, Ohio in the Midwestern United States from 1990 to 2010. It underscores the local-scale nature of such vulnerability, and provides evidence for local scale vulnerability assessments such as is conducted by the Extreme Heat Vulnerability Index (EHVI) (D. P. Johnson et al., 2012). Further, the study represents the benefits of including satellite-based measures of the physical environment by utilizing measures of NDVI, NDBI, and LST. The study demonstrated there are significant spatial and temporal variations in extreme heat vulnerability within each of the three cities examined, and supports previous studies which highlighted urban sprawl as a vulnerable factor itself (Stone. et al., 2010).

The study also highlights the need for further studies projecting the future extent of extreme heat vulnerability. The latest National Assessment on climate change in the United States indicates the Midwest as being particularly vulnerable to extreme heat events. Utilizing methods demonstrated in this analysis, it could be possible to make projections of changes in land use and the physical environment to match future long-term climate forecasts, and make predictions on what kind of weather mitigation plans would be necessary within city planning projects. This could be employed to develop future scenarios for individual cities, to assist in the assessment and preparation for future impacts of a changing climate at the local scale.

The method outlined in this study is a developing methodology and as newer space borne and airborne sensors become available, they can readily be incorporated into such methodology. 
The continual development of newer more advanced sensor technology is an exciting trend for vulnerability analysis and should only make the efforts of researchers interested in vulnerability more accurate and precise. This is vital for the future of research dealing with the social implications of climate change and its related phenomena. 


\section{References}

Bird., Eric, Dorworth., Leslie, \& McCormick., Robert. (2010). Climate Change Are you preparing for it? Purdue University Cooperative Extension Service (Vol. FNR-425-W).

Browning, C. R., Wallace, D., Feinberg, S. L., \& Cagney, K. A. (2006). Neighborhood social processes, physical conditions, and disaster-related mortality: The case of the 1995 Chicago heat wave. American Sociological Review, 71(4), 661-678.

Changnon., Stanley A., Kunkel., Kenneth E., \& Reinke., Beth C. (1996). Impacts and Responses to the 1995 Heat Wave: A Call to Action. Bulletin of the American Meteorological Society, 77(7).

Cutter, S. L., Burton, C. G., \& Emrich, C. T. (2010). Disaster Resilience Indicators for Benchmarking Baseline Conditions. Journal of Homeland Security and Emergency Management, 7(1). doi: Artn 51

Dan Johnson, Vijay Lulla, Austin Stanforth, Jeremy Webber. (2011). Remote Sensing of Heat-Related Health Risk: The Trend Toward Coupling Socioeconmic and Remotely Sensed Data. Geography Compass, 5(10), 767-780.

Dousset, B., \& Gourmelon, F. (2003). Satellite multi-sensor data analysis of urban surface temperatures and landcover. Isprs Journal of Photogrammetry and Remote Sensing, 58(1-2), 43-54. doi: Doi 10.1016/S0924-2716(03)00016-9

Fry, J., Xian, G., Jin, S., Dewitz, J., Homer, C., Yang, L., Barnes, C., Herold, N., and Wickham, J. (2011). Completion of the 2006 National Land Cover Database for the Conterminous United States. $P E \& R S, 77(9), 858-864$. 
Harlan, S. L., Brazel, A. J., Prashad, L., Stefanov, W. L., \& Larsen, L. (2006). Neighborhood microclimates and vulnerability to heat stress. Social Science \& Medicine, 63(11), 2847-2863.

Harlan., Sharon L., Declet-Barreto., Juan H., Stefanov., William L., \& Petitti., Diana B. (2013). Neighborhood Effects on Heat Deaths: Social and Environmental Predictors of Vulnerability in Maricopa County, Arizona. Environmental Health Perspectives, 121(2). Homer, C., Dewitz, J., Fry, J., Coan, M., Hossain, N., Larson, C., Herold, N., McKerrow, A., VanDriel, J.N., and Wickham, J. (2007). Completion of the 2001 National Land Cover Database for the Conterminous United States. Photogrammetric Engineering and Remote Sensing, 73(4), 337-341.

Hondula., David M, Davis., Robert E, Leisten., Matthew J, Saha., Michael V, Veazey., Lindsay M, \& Wegner, Carleigh R. (2012). Fine-scale spatial variability of heat-related mortality in Philadelphia County, USA, from 1983-2008: a case-series analysis. Environmental Health, 11(16).

Horton, Radley, Rosenzweig, Cynthia, Ramaswamy, V., Kinney, Patrick, Mathu, Rohit, Pleim, Jonathan, \& Rao, V. Brahmananda. (2010). Integrated Climate Change Information for Resilient Adaptation Planning Air \& Waste Management

Jackson, R., \& Shields, K. N. (2008). Preparing the US health community for climate change. Annual Review of Public Health, 29, 57-+.

Jensen, John R. (2005). Introductory Remote Sensing - A Remote Sensing Perspective (3 ed.). Upper Saddle River: Pearson - Prentice Hall.

Johnson, D. P., Stanforth, A.C. , Lulla, V., \& Luber, G.C. (2012). Developing an applied extreme heat vulnerability index. Applied Geography. 
Johnson, D. P., \& Wilson, J. S. (2009). The socio-spatial dynamics of extreme urban heat events: The case of heat-related deaths in Philadelphia. Applied Geography, 29(3), 419-434.

Johnson, Daniel, Wilson, Jeffrey, \& Luber, George. (2009). Socioeconomic indicators of heatrelated health risk supplemented with remotely sensed data. International Journal of Health Geographics, 8(1), 57.

Kalkstein, Laurence S. (1991). A New Approach to Evaluate the Impact of Climate on Human Mortality. Environmental Health Perspectives, 96, 145-150.

Kalkstein, Laurence S., \& Greene, J. Scott. (1997). An Evaluation of Climate/Mortality Relationships in Large U.S. Cities and the Possible Impacts of a Climate Change. Environmental Health Perspectives, 105(1), 84-93.

Kalkstein, Laurence S., Jamason, Paul F., Greene, J. Scott, Libby, Jerry, \& Robinson, Lawrence. (1996). The Philadelphia Hot Weather-Health Watch/Warning System: Development and Application, Summer 1995. Bulletin of the American Meteorological Society, 77(7), 1520-1528.

Luber, G., \& McGeehin, M. (2008). Climate Change and Extreme Heat Events. American Journal of Preventive Medicine, 35(5), 429-435. doi: DOI 10.1016/j.amepre.2008.08.021

Moran, P. A. P. (1950). Notes on Continuous Stochastic Phenomena. Biometrika, 37(1/2), $17-23$.

Patz, J. A., McGeehin, M. A., Bernard, S. M., Ebi, K. L., Epstein, P. R., Grambsch, A., . . Trtanj, J. (2000). The potential health impacts of climate variability and change for the United 
States: Executive summary of the report of the health sector of the US National Assessment. Environmental Health Perspectives, 108(4), 367-376.

Reid., Colleen E., Mann., Jennifer K., Alfasso., Ruth, English., Paul B., King., Galatea C., Lincoln., Rebecca A., ... Balmes., John R. (2012). Evaluation of a Heat Vulnerability Index on Abnormally Hot Days:

An Environmental Public Health Tracking Study. Environmental Health Perspectives, 120(5).

Shen, T., Howe, H.L., Alo, C., \& Moolenaar, R.L. (1998). Toward a broader definition of heatrelated death: comparison of mortality estimates from medical examiners' classification with those from total death differentials during the July 1995 heat wave in Chicago, Illinois. The American journal of forensic medicine and pathology, 19(2), 113.

Stone., Brian, Hess., Jeremy J., \& Frumkin., Howard. (2010). Urban Form and Extreme Heat Events: Are Sprawling Cities More Vulnerable to Climate Change Than Compact Cities? Environmental Health Perspectives, 118, 1425-1428.

Uejio, C. K., Wilhelmi, O. V., Golden, J. S., Mills, D. M., Gulino, S. P., \& Samenow, J. P. (2011). Intra-urban societal vulnerability to extreme heat: The role of heat exposure and the built environment, socioeconomics, and neighborhood stability. Health \& Place, 17(2), 498-507. doi: Doi 10.1016/J.Healthplace.2010.12.005

Unites States Geological Survey, Earth Explorer. (2009). Landsat Product Type Descriptions. Retrieved 05-16-12, 2011, from http://edcsns17.cr.usgs.gov/helpdocs/landsat/product_descriptions.html - terrain_15_11t 
Weng, Q. H., Lu, D. S., \& Schubring, J. (2004). Estimation of land surface temperaturevegetation abundance relationship for urban heat island studies. Remote Sensing of Environment, 89(4), 467-483. doi: DOI 10.1016/j.rse.2003.11.005

Wilhelmi, O. V., \& Hayden, M. H. (2010). Connecting people and place: a new framework for reducing urban vulnerability to extreme heat. Environmental Research Letters, 5(1), - 


\section{List Tables and Figures}

1 Table 1 (a) Chicago 1990 EHIV Loadings

2 Table 1 (b) Chicago 2000 EHVI Loadings

3 Table 1 (c) Chicago 2010 EHVI Loadings

4 Table 2 (a) Indianapolis EHVI 1990 Loadings

5 Table 2 (b) Indianapolis EHVI 2000 Loadings

6 Table 2 (c) Indianapolis EHVI 2010 Loadings

7 Table 3 (a) Dayton 1990 EHVI Loadings

8 Table 3 (b) Dayton 2000 EHVI Loadings

9 Table 3 (c) Dayton 2010 EHVI Loadings

10 Table 4 Table 4 Morans $I$ Spatial Auto Correlation

11 Figure 1 Landsat 5 Thermal Imagery Percentiles

12 Figure 2 Chicago EHVI 1990, 2000, and 2010 Map

13 Figure 3 Indianapolis EHVI 1990, 2000, and 2010 Map

14 Figure 4 Dayton EHVI 1990, 2000, and 2010 Map 
Tables $1-3$. EHVI Loadings by City

Table 1 (a). Chicago 1990 EHVI Loadings

The Loadings

\begin{tabular}{lcccccc|}
\hline \multicolumn{1}{c}{ 1990 Chicago } & \multicolumn{7}{c|}{ Components } \\
\hline \multicolumn{1}{c}{ Vulnerability Factors } & PC1 & PC2 & PC3 & PC4 & PC5 & Total \% Variance \\
\hline Total Population & 0.919 & -0.008 & 0.117 & -0.001 & -0.065 & \\
Total 25 and over no High School Degree & 0.840 & -0.374 & 0.084 & -0.095 & -0.120 & \\
Male Age 65 and Older & 0.807 & 0.461 & -0.016 & 0.098 & -0.147 & \\
Total Under Age 5 & 0.780 & -0.473 & 0.191 & -0.150 & -0.065 & \\
Male Under Age 5 & 0.771 & -0.560 & 0.204 & 0.058 & -0.096 \\
Female Under Age 5 & 0.767 & -0.570 & 0.192 & 0.051 & -0.103 & \\
Female Age 65 and Older & 0.766 & 0.555 & -0.049 & 0.071 & -0.175 & \\
Total Age 65 and Older & 0.761 & 0.578 & -0.047 & 0.058 & -0.160 & \\
Total Below Poverty & 0.701 & -0.380 & 0.098 & -0.476 & 0.064 & \\
Total 65 and Older Living Alone & 0.697 & 0.627 & -0.075 & -0.057 & -0.145 & \\
Male 65 and Older Living Alone & 0.676 & 0.486 & -0.057 & -0.122 & -0.078 & \\
Total 65 and Older Below Poverty & 0.673 & 0.219 & 0.010 & -0.380 & 0.219 & \\
Female 65 and Older Living Alone & 0.664 & 0.636 & -0.076 & -0.033 & -0.158 & \\
White & 0.635 & 0.336 & 0.061 & 0.485 & -0.087 & \\
American Indian & 0.621 & -0.101 & 0.152 & 0.129 & 0.425 & \\
Hispanic & 0.612 & -0.575 & 0.156 & 0.388 & -0.138 & \\
Other & 0.559 & -0.594 & 0.157 & 0.369 & -0.164 & \\
Normalized Difference Built-Up Index & 0.311 & -0.210 & -0.837 & 0.090 & 0.139 & \\
Normalized Difference Vegetation Index & -0.394 & 0.205 & 0.826 & -0.114 & -0.093 & \\
Land Surface Temperature & 0.302 & -0.326 & -0.725 & 0.126 & 0.011 & \\
Median Household Income 1989 & -0.332 & 0.246 & 0.474 & 0.267 & 0.011 & \\
Black & 0.348 & -0.158 & 0.005 & -0.851 & -0.066 & \\
Pacific Islander & 0.526 & 0.165 & 0.145 & 0.055 & 0.664 & \\
Asian & 0.556 & 0.149 & 0.156 & 0.147 & 0.663 & \\
\hline \hline Percent Variance Explained & 26.89 & 24.68 & 12.02 & 9.89 & 9.74 & 83.22 \\
\hline & & & & & & \\
& & & & &
\end{tabular}


Table 1 (b). Chicago 2000 EHVI Loadings

The Loadings

\begin{tabular}{lcccccc|}
\hline \multicolumn{1}{c}{ 2000 Chicago } & \multicolumn{6}{c|}{ Components } \\
\hline \multicolumn{1}{c}{ Vulnerability Factors } & PC1 & PC2 & PC3 & PC4 & PC5 & Total \% Variance \\
\hline Total 65 and Older Living Alone & 0.955 & 0.031 & 0.096 & 0.063 & -0.028 & \\
Total Age 65 and Older & 0.923 & 0.092 & 0.190 & 0.046 & 0.122 & \\
Female 65 and OIder Living Alone & 0.920 & 0.020 & 0.083 & 0.048 & -0.026 & \\
Female Age 65 and Older & 0.900 & 0.069 & 0.198 & 0.049 & 0.091 & \\
Male Age 65 and Older & 0.866 & 0.117 & 0.159 & 0.037 & 0.158 & \\
Male 65 and Older Living Alone & 0.831 & 0.047 & 0.101 & 0.081 & -0.025 & \\
Total 65 and Older Below Poverty & 0.611 & 0.019 & 0.466 & 0.109 & -0.008 & \\
White & 0.542 & 0.505 & -0.270 & 0.060 & 0.396 & \\
Hispanic & 0.014 & 0.922 & 0.064 & 0.171 & 0.093 & \\
Other & -0.017 & 0.904 & 0.062 & 0.158 & 0.035 & \\
Total Under Age 5 & 0.073 & 0.753 & 0.574 & 0.102 & 0.074 & \\
Female Under Age 5 & 0.063 & 0.716 & 0.540 & 0.092 & 0.063 & \\
Male Under Age 5 & 0.075 & 0.715 & 0.551 & 0.102 & 0.078 & \\
Total Population & 0.491 & 0.613 & 0.417 & 0.148 & 0.260 & \\
American Indian & 0.074 & 0.477 & 0.024 & 0.065 & -0.130 & \\
Black & 0.127 & -0.162 & 0.867 & 0.053 & -0.191 & \\
Total 25 and over no High School Degree & 0.233 & 0.308 & 0.769 & 0.166 & 0.220 & \\
Female 25 and over no High School Degree & 0.232 & 0.203 & 0.747 & 0.136 & 0.135 & \\
Total Below Poverty & 0.205 & 0.423 & 0.736 & 0.152 & 0.014 & \\
Male 25 and over no High School Degree & 0.179 & 0.343 & 0.609 & 0.157 & 0.255 & \\
Normalized Difference Built-Up Index & 0.098 & 0.081 & 0.103 & 0.942 & 0.040 & \\
Normalized Difference Vegetation Index & -0.161 & -0.208 & -0.090 & -0.910 & -0.101 & \\
Land Surface Temperature & -0.017 & 0.241 & 0.161 & 0.837 & 0.061 & \\
Median Household Income 1999 & -0.096 & -0.051 & -0.464 & -0.530 & 0.208 & \\
Pacific Islander & -0.065 & -0.047 & 0.070 & 0.015 & 0.654 & \\
Asian & 0.336 & 0.100 & 0.061 & 0.061 & 0.601 & \\
\hline \hline Percent Variance Explained & 23.660 & 18.190 & 17.710 & 11.310 & 5.120 & 75.99 \\
\hline & & & & & & \\
& & & &
\end{tabular}


Table 1 (c). Chicago 2010 EHVI Loadings

The Loadings

\begin{tabular}{|c|c|c|c|c|c|}
\hline 2010 Chicago & & Comp & onents & & \\
\hline Vulnerability Factors & PC1 & $\mathrm{PC} 2$ & PC3 & PC4 & Total \% Variance \\
\hline Male Age 65 and Older & 0.924 & 0.065 & 0.016 & 0.066 & \\
\hline Total Age 65 and Older & 0.914 & 0.056 & 0.011 & 0.102 & \\
\hline Female Age 65 and Older & 0.897 & 0.049 & 0.007 & 0.125 & \\
\hline Total Population & 0.894 & 0.348 & 0.194 & -0.012 & \\
\hline White & 0.894 & 0.348 & 0.194 & -0.012 & \\
\hline Male Under Age 5 & 0.876 & 0.389 & 0.180 & -0.023 & \\
\hline Total Under Age 5 & 0.868 & 0.408 & 0.185 & -0.019 & \\
\hline Asian & 0.796 & 0.216 & -0.019 & -0.033 & \\
\hline Hispanic & 0.064 & 0.892 & 0.238 & -0.202 & \\
\hline Other & -0.024 & 0.887 & 0.231 & -0.186 & \\
\hline Total 25 and over no High School Degree & 0.395 & 0.829 & 0.062 & 0.255 & \\
\hline Male 25 and over no High School Degree & 0.273 & 0.824 & 0.119 & 0.182 & \\
\hline American Indian & 0.272 & 0.734 & 0.162 & -0.103 & \\
\hline Female 25 and over no High School Degree & 0.447 & 0.732 & 0.007 & 0.283 & \\
\hline Female Under Age 5 & 0.545 & 0.691 & 0.240 & 0.068 & \\
\hline Normalized Difference Built-Up Index & 0.144 & 0.170 & 0.911 & 0.108 & \\
\hline Normalized Difference Vegetation Index & -0.257 & -0.182 & -0.861 & -0.004 & \\
\hline Land Surface Temperature & -0.342 & 0.326 & 0.456 & 0.099 & \\
\hline Black & 0.365 & -0.017 & 0.207 & 0.707 & \\
\hline Median Household Income 2009 & 0.055 & -0.224 & -0.493 & -0.594 & \\
\hline Pacific Islander & 0.190 & 0.128 & 0.315 & -0.426 & \\
\hline Percent Variance Explained & 35.380 & 25.490 & 11.990 & 6.460 & 79.32 \\
\hline
\end{tabular}


Table 2 (a). Indianapolis EHVI 1990 Loadings

The Loadings

\begin{tabular}{|c|c|c|c|c|c|}
\hline \multirow{2}{*}{$\begin{array}{c}1990 \text { Indianapolis } \\
\text { Vulnerability Factors }\end{array}$} & \multicolumn{4}{|c|}{ Components } & \multirow[b]{2}{*}{ Total \% Variance } \\
\hline & PC1 & $\mathrm{PC} 2$ & PC3 & PC4 & \\
\hline Male Age 65 and Older & 0.968 & 0.095 & -0.020 & -0.007 & \\
\hline Total Age 65 and Older & 0.965 & 0.118 & -0.007 & 0.000 & \\
\hline Black & 0.957 & -0.121 & 0.044 & 0.097 & \\
\hline Total 65 and Older Living Alone & 0.951 & 0.085 & 0.042 & -0.002 & \\
\hline Female Age 65 and Older & 0.951 & 0.136 & 0.004 & 0.006 & \\
\hline Male 65 and Older Living Alone & 0.946 & -0.009 & 0.025 & 0.041 & \\
\hline Total 25 and over no High School Degree & 0.941 & 0.161 & 0.147 & -0.002 & \\
\hline Total 65 and Older Below Poverty & 0.936 & -0.080 & 0.130 & -0.056 & \\
\hline Total Under Age 5 & 0.924 & 0.282 & 0.052 & 0.114 & \\
\hline Male Under Age 5 & 0.924 & 0.280 & 0.054 & 0.118 & \\
\hline Female Under Age 5 & 0.916 & 0.294 & 0.049 & 0.108 & \\
\hline Total Population & 0.916 & 0.330 & 0.020 & 0.152 & \\
\hline Total Below Poverty & 0.915 & 0.097 & 0.16 & 0.087 & \\
\hline Female 65 and Older Living Alone & 0.891 & 0.139 & 0.05 & -0.030 & \\
\hline Hispanic & 0.659 & 0.644 & 0.133 & 0.130 & \\
\hline White & 0.108 & 0.861 & -0.041 & 0.099 & \\
\hline American Indian & 0.055 & 0.757 & 0.098 & 0.002 & \\
\hline Other & 0.248 & 0.736 & 0.125 & 0.262 & \\
\hline Normalized Difference Vegetation Index & -0.02 & -0.102 & -0.928 & -0.028 & \\
\hline Normalized Difference Built-Up Index & -0.027 & 0.032 & 0.886 & 0.031 & \\
\hline Land Surface Temperature & 0.099 & 0.197 & 0.752 & -0.022 & \\
\hline Median Household Income 1989 & -0.109 & 0.077 & -0.584 & -0.033 & \\
\hline Pacific Islander & 0.057 & 0.111 & 0.034 & 0.888 & \\
\hline Asian & 0.058 & 0.171 & 0.029 & 0.883 & \\
\hline Percent Variance Explained & 53.38 & 11.86 & 11.17 & 7.30 & 83.71 \\
\hline
\end{tabular}


Table 2 (b). Indianapolis EHVI 2000 Loadings

The Loadings

\begin{tabular}{|c|c|c|c|c|c|c|c|}
\hline \multirow{2}{*}{$\begin{array}{l}2000 \text { Indianapolis } \\
\text { Vulnerability Factors }\end{array}$} & \multicolumn{6}{|c|}{ Components } & \multirow[b]{2}{*}{ Total \% Variance } \\
\hline & PC1 & PC2 & $\mathrm{PC} 3$ & PC4 & PC5 & PC6 & \\
\hline Total Under Age 5 & 0.926 & 0.094 & -0.043 & 0.235 & 0.05 & 0.133 & \\
\hline Male Under Age 5 & 0.914 & 0.102 & -0.035 & 0.220 & 0.050 & 0.130 & \\
\hline Female Under Age 5 & 0.909 & 0.083 & -0.051 & 0.243 & 0.049 & 0.131 & \\
\hline Total Population & 0.833 & 0.374 & -0.095 & 0.218 & -0.022 & 0.178 & \\
\hline Total Below Poverty & 0.638 & 0.157 & 0.248 & 0.306 & 0.430 & 0.055 & \\
\hline Female 25 and over no High School Degree & 0.625 & 0.358 & 0.236 & 0.353 & 0.293 & -0.223 & \\
\hline Total 25 and over no High School Degree & 0.62 & 0.308 & 0.251 & 0.474 & 0.259 & -0.228 & \\
\hline Male 25 and over no High School Degree & 0.557 & 0.227 & 0.244 & 0.554 & 0.200 & -0.212 & \\
\hline Total 65 and Older Living Alone & 0.05 & 0.918 & 0.086 & 0.118 & 0.068 & 0.058 & \\
\hline Female Age 65 and Older & 0.232 & 0.888 & -0.142 & -0.07 & -0.054 & 0.000 & \\
\hline Female 65 and Older Living Alone & 0.066 & 0.856 & 0.068 & 0.032 & 0.016 & 0.062 & \\
\hline Total Age 65 and Older & 0.233 & 0.850 & -0.155 & -0.070 & -0.076 & -0.015 & \\
\hline Male Age 65 and Older & 0.310 & 0.791 & -0.272 & -0.051 & -0.103 & -0.040 & \\
\hline Male 65 and Older Living Alone & -0.009 & 0.684 & 0.093 & 0.272 & 0.162 & 0.0230 & \\
\hline Total 65 and Older Below Poverty & 0.111 & 0.594 & 0.226 & 0.041 & 0.436 & -0.029 & \\
\hline Normalized Difference Built-Up Index & -0.071 & -0.140 & 0.940 & 0.039 & -0.012 & 0.016 & \\
\hline Normalized Difference Vegetation Index & 0.043 & 0.058 & -0.936 & -0.064 & 0.014 & 0.017 & \\
\hline Land Surface Temperature & 0.101 & 0.043 & 0.905 & 0.149 & 0.014 & 0.027 & \\
\hline Median Household Income 1999 & -0.103 & -0.095 & -0.601 & -0.105 & -0.457 & 0.071 & \\
\hline Hispanic & 0.339 & -0.033 & 0.079 & 0.840 & -0.001 & 0.226 & \\
\hline Other & 0.436 & -0.015 & 0.079 & 0.797 & 0.021 & 0.247 & \\
\hline American Indian & 0.389 & 0.095 & 0.143 & 0.619 & -0.055 & -0.022 & \\
\hline Black & 0.409 & 0.116 & -0.064 & 0.009 & 0.806 & 0.061 & \\
\hline White & 0.572 & 0.341 & -0.073 & 0.126 & -0.665 & 0.079 & \\
\hline Asian & 0.116 & 0.065 & 0.004 & -0.038 & 0.028 & 0.860 & \\
\hline Pacific Islander & 0.129 & 0.009 & -0.008 & 0.344 & -0.037 & 0.669 & \\
\hline Percent Variance Explained & 22.84 & 19.09 & 13.18 & 11.38 & 7.44 & 6.00 & 79.93 \\
\hline
\end{tabular}


Table 2 (c). Indianapolis EHVI 2010 Loadings

The Loadings

\begin{tabular}{|c|c|c|c|c|c|c|}
\hline \multirow{2}{*}{$\begin{array}{l}2010 \text { Indianapolis } \\
\text { Vulnerability Factors }\end{array}$} & \multicolumn{5}{|c|}{ Components } & \multirow[b]{2}{*}{ Total \% Variance } \\
\hline & PC1 & PC2 & PC3 & PC4 & PC5 & \\
\hline Total Under Age 5 & 0.947 & -0.009 & -0.013 & 0.215 & -0.085 & \\
\hline Female Under Age 5 & 0.937 & -0.006 & -0.012 & 0.208 & -0.086 & \\
\hline Male Under Age 5 & 0.935 & -0.011 & -0.014 & 0.217 & -0.081 & \\
\hline Total Population & 0.870 & -0.054 & 0.279 & 0.175 & 0.084 & \\
\hline Hispanic & 0.814 & 0.103 & -0.113 & 0.326 & 0.002 & \\
\hline Other & 0.805 & 0.104 & -0.130 & 0.302 & -0.034 & \\
\hline American Indian & 0.522 & 0.093 & -0.033 & 0.456 & 0.103 & \\
\hline Asian & 0.440 & 0.185 & 0.137 & -0.312 & 0.235 & \\
\hline Pacific Islander & 0.291 & 0.031 & -0.100 & 0.219 & 0.167 & \\
\hline Normalized Difference Built-Up Index & 0.008 & 0.933 & -0.214 & 0.063 & -0.027 & \\
\hline Normalized Difference Vegetation Index & -0.005 & -0.923 & 0.170 & -0.072 & -0.001 & \\
\hline Land Surface Temperature & 0.065 & 0.920 & -0.076 & 0.201 & 0.027 & \\
\hline Median Household Income 2009 & -0.116 & -0.537 & -0.008 & -0.401 & 0.427 & \\
\hline Total Age 65 and Older & -0.017 & -0.132 & 0.979 & 0.030 & 0.038 & \\
\hline Female Age 65 and Older & -0.010 & -0.055 & 0.964 & 0.018 & 0.007 & \\
\hline Male Age 65 and Older & -0.029 & -0.270 & 0.911 & 0.052 & 0.094 & \\
\hline Total 25 and over no High School Degree & 0.387 & 0.180 & 0.083 & 0.860 & -0.051 & \\
\hline Male 25 and over no High School Degree & 0.344 & 0.152 & 0.012 & 0.802 & -0.012 & \\
\hline Female 25 and over no High School Degree & 0.364 & 0.177 & 0.138 & 0.772 & -0.081 & \\
\hline White & 0.330 & -0.101 & 0.294 & 0.053 & 0.806 & \\
\hline Black & 0.489 & -0.039 & 0.106 & 0.102 & -0.782 & \\
\hline Percent Variance Explained & 28.738 & 14.849 & 14.576 & 13.918 & 7.558 & 79.639 \\
\hline
\end{tabular}


Table 3 (a). Dayton 1990 EHVI Loadings

The Loadings

\begin{tabular}{|c|c|c|c|c|c|c|}
\hline \multirow{2}{*}{$\begin{array}{c}1990 \text { Dayton } \\
\text { Vulnerability Factors }\end{array}$} & \multicolumn{5}{|c|}{ Components } & \multirow[b]{2}{*}{ Total \% Variance } \\
\hline & PC1 & PC2 & PC3 & PC4 & PC5 & \\
\hline Male Age 65 and Older & 0.964 & 0.035 & -0.057 & 0.063 & -0.004 & \\
\hline Total Age 65 and Older & 0.960 & 0.034 & -0.046 & 0.019 & -0.025 & \\
\hline Female Age 65 and Older & 0.945 & 0.033 & -0.038 & -0.007 & -0.038 & \\
\hline White & 0.896 & 0.061 & -0.070 & 0.327 & -0.147 & \\
\hline Total Population & 0.891 & 0.092 & -0.043 & 0.340 & 0.236 & \\
\hline Male Under Age 5 & 0.749 & 0.084 & 0.002 & 0.373 & 0.381 & \\
\hline Total Under Age 5 & 0.748 & 0.089 & 0.000 & 0.380 & 0.384 & \\
\hline Female Under Age 5 & 0.737 & 0.093 & -0.004 & 0.391 & 0.380 & \\
\hline American Indian & 0.509 & -0.044 & 0.033 & 0.208 & 0.449 & \\
\hline Median Household Income 1989 & 0.353 & -0.094 & -0.270 & 0.061 & -0.192 & \\
\hline Total 65 and Older Living Alone & 0.096 & 0.919 & 0.067 & 0.171 & -0.061 & \\
\hline Female 65 and Older Living Alone & 0.124 & 0.889 & 0.067 & 0.206 & -0.036 & \\
\hline Total 65 and Older Below Poverty & -0.029 & 0.873 & 0.145 & -0.112 & 0.037 & \\
\hline Male 65 and Older Living Alone & -0.028 & 0.825 & 0.052 & 0.009 & -0.139 & \\
\hline Total 25 and over no High School Degree & 0.086 & 0.792 & 0.080 & -0.007 & 0.227 & \\
\hline Total Below Poverty & 0.000 & 0.757 & 0.186 & -0.006 & 0.281 & \\
\hline Normalized Difference Vegetation Index & 0.061 & -0.157 & -0.960 & -0.019 & 0.005 & \\
\hline Normalized Difference Built-Up Index & -0.096 & 0.151 & 0.950 & -0.016 & 0.010 & \\
\hline Land Surface Temperature & -0.004 & 0.135 & 0.926 & 0.099 & 0.069 & \\
\hline Asian & 0.256 & -0.009 & 0.072 & 0.774 & -0.027 & \\
\hline Hispanic & 0.495 & 0.103 & -0.044 & 0.695 & 0.130 & \\
\hline Pacific Islander & 0.084 & 0.002 & 0.003 & 0.676 & 0.008 & \\
\hline Other & 0.213 & 0.245 & 0.071 & 0.572 & 0.417 & \\
\hline Black & 0.055 & 0.076 & 0.055 & 0.034 & 0.883 & \\
\hline Percent Variance Explained & 28.34 & 18.63 & 11.91 & 11.14 & 7.86 & 77.88 \\
\hline
\end{tabular}


Table 3 (b). Dayton 2000 EHVI Loading

The Loadings

\begin{tabular}{|c|c|c|c|c|c|c|c|c|}
\hline \multirow{2}{*}{$\begin{array}{c}2000 \text { Dayton } \\
\text { Vulnerability Factors }\end{array}$} & \multicolumn{7}{|c|}{ Components } & \multirow[b]{2}{*}{ Total \% Variance } \\
\hline & PC1 & $\mathrm{PC} 2$ & PC3 & $\mathrm{PC} 4$ & PC5 & PC6 & PC7 & \\
\hline Total 65 and Older Living Alone & 0.961 & 0.050 & -0.102 & 0.099 & 0.002 & -0.016 & -0.026 & \\
\hline Female 65 and Older Living Alone & 0.929 & 0.011 & -0.077 & 0.080 & -0.051 & -0.046 & -0.057 & \\
\hline Female Age 65 and Older & 0.846 & 0.031 & -0.275 & -0.069 & -0.061 & -0.196 & 0.106 & \\
\hline Total Age 65 and Older & 0.744 & 0.145 & -0.396 & -0.154 & -0.095 & -0.215 & 0.225 & \\
\hline Male 65 and Older Living Alone & 0.709 & 0.141 & -0.136 & 0.116 & 0.147 & 0.073 & 0.072 & \\
\hline Total 65 and Older Below Poverty & 0.596 & 0.283 & -0.073 & 0.265 & 0.343 & 0.001 & 0.062 & \\
\hline Total 25 and Older No High School Degree & 0.146 & 0.924 & 0.008 & 0.196 & 0.146 & 0.058 & 0.060 & \\
\hline Male 25 and over no High School Degree & -0.026 & 0.880 & -0.120 & 0.116 & 0.098 & 0.083 & 0.114 & \\
\hline Female 25 and over no High School Degree & 0.293 & 0.740 & 0.142 & 0.232 & 0.162 & 0.017 & -0.012 & \\
\hline Median Household Income 1999 & -0.150 & -0.537 & -0.226 & -0.373 & -0.351 & -0.232 & 0.189 & \\
\hline Asian & -0.095 & -0.499 & -0.036 & -0.006 & -0.223 & 0.216 & 0.367 & \\
\hline Total Under Age 5 & -0.229 & 0.053 & 0.948 & 0.024 & 0.079 & 0.101 & 0.011 & \\
\hline Female Under Age 5 & -0.215 & 0.030 & 0.897 & 0.009 & 0.075 & 0.086 & -0.006 & \\
\hline Male Under Age 5 & -0.217 & 0.069 & 0.890 & 0.036 & 0.074 & 0.104 & 0.027 & \\
\hline Male Age 65 and Older & 0.413 & 0.267 & -0.462 & -0.231 & -0.118 & -0.186 & 0.333 & \\
\hline Normalized Difference Vegetation Index & -0.089 & -0.255 & -0.019 & -0.908 & -0.036 & -0.165 & -0.039 & \\
\hline Normalized Difference Built-Up Index & -0.019 & 0.235 & -0.007 & 0.868 & -0.004 & 0.010 & 0.090 & \\
\hline Land Surface Temperature & 0.126 & 0.063 & 0.090 & 0.828 & 0.055 & 0.128 & -0.119 & \\
\hline White & -0.008 & -0.169 & -0.081 & -0.005 & -0.959 & 0.004 & 0.027 & \\
\hline Black & 0.016 & 0.185 & 0.074 & 0.001 & 0.955 & -0.049 & -0.039 & \\
\hline Total Below Poverty & 0.074 & 0.435 & 0.348 & 0.248 & 0.550 & 0.238 & -0.077 & \\
\hline Hispanic & -0.090 & -0.062 & 0.070 & 0.128 & -0.068 & 0.859 & 0.034 & \\
\hline Other & -0.104 & -0.045 & 0.178 & 0.083 & 0.221 & 0.782 & -0.015 & \\
\hline American Indian & -0.023 & 0.267 & 0.062 & 0.066 & -0.100 & 0.554 & 0.004 & \\
\hline Total Population & -0.137 & -0.154 & 0.172 & 0.174 & 0.085 & 0.120 & -0.753 & \\
\hline Pacific Islander & 0.061 & -0.132 & 0.194 & 0.202 & 0.042 & 0.125 & 0.506 & \\
\hline Percent Variance Explained & 17.08 & 13.12 & 12.76 & 10.98 & 10.10 & 7.90 & 4.73 & 76.67 \\
\hline
\end{tabular}


Table 3 (c). Dayton 2010 EHVI Loadings

The Loadings

\begin{tabular}{|c|c|c|c|c|c|c|}
\hline \multirow{2}{*}{$\begin{array}{c}2010 \text { Dayton } \\
\text { Vulnerability Factors }\end{array}$} & \multicolumn{5}{|c|}{ Components } & \multirow[b]{2}{*}{ Total \% Variance } \\
\hline & PC1 & PC2 & PC3 & PC4 & PC5 & \\
\hline Total Under Age 5 & 0.951 & -0.004 & 0.172 & 0.026 & -0.096 & \\
\hline Female Under Age 5 & 0.938 & 0.005 & 0.146 & 0.030 & -0.098 & \\
\hline Male Under Age 5 & 0.933 & -0.013 & 0.191 & 0.022 & -0.091 & \\
\hline Total Population & 0.717 & 0.460 & 0.217 & 0.030 & 0.168 & \\
\hline Hispanic & 0.620 & -0.157 & 0.487 & 0.198 & 0.371 & \\
\hline American Indian & 0.618 & 0.092 & 0.178 & 0.125 & 0.097 & \\
\hline Pacific Islander & 0.153 & -0.095 & -0.005 & 0.066 & 0.049 & \\
\hline Total Age 65 and Older & -0.002 & 0.973 & 0.119 & -0.075 & 0.008 & \\
\hline Male Age 65 and Older & 0.030 & 0.947 & 0.093 & -0.168 & 0.075 & \\
\hline Female Age 65 and Older & -0.024 & 0.943 & 0.130 & -0.010 & -0.037 & \\
\hline Total 25 and over no High School Degree & 0.213 & 0.203 & 0.905 & 0.126 & -0.155 & \\
\hline Male 25 and over no High School Degree & 0.148 & 0.150 & 0.823 & 0.112 & -0.126 & \\
\hline Female 25 and over no High School Degree & 0.231 & 0.212 & 0.798 & 0.114 & -0.150 & \\
\hline Other & 0.443 & -0.202 & 0.594 & 0.189 & 0.310 & \\
\hline Normalized Difference Vegetation Index & -0.035 & 0.134 & -0.119 & -0.958 & -0.018 & \\
\hline Normalized Difference Built-Up Index & 0.029 & -0.123 & 0.099 & 0.911 & -0.008 & \\
\hline Land Surface Temperature & 0.184 & 0.031 & 0.101 & 0.829 & -0.044 & \\
\hline Median Household Income 2009 & -0.092 & 0.072 & -0.350 & -0.510 & 0.483 & \\
\hline Black & 0.265 & 0.044 & 0.112 & 0.039 & -0.844 & \\
\hline White & 0.436 & 0.412 & 0.108 & -0.008 & 0.686 & \\
\hline Asian & 0.290 & -0.062 & -0.232 & -0.023 & 0.419 & \\
\hline Percent Variance Explained & 22.22 & 15.96 & 15.08 & 13.66 & 9.36 & 76.28 \\
\hline
\end{tabular}


Figure 1. Landsat 5 Thermal Imagery Percentiles
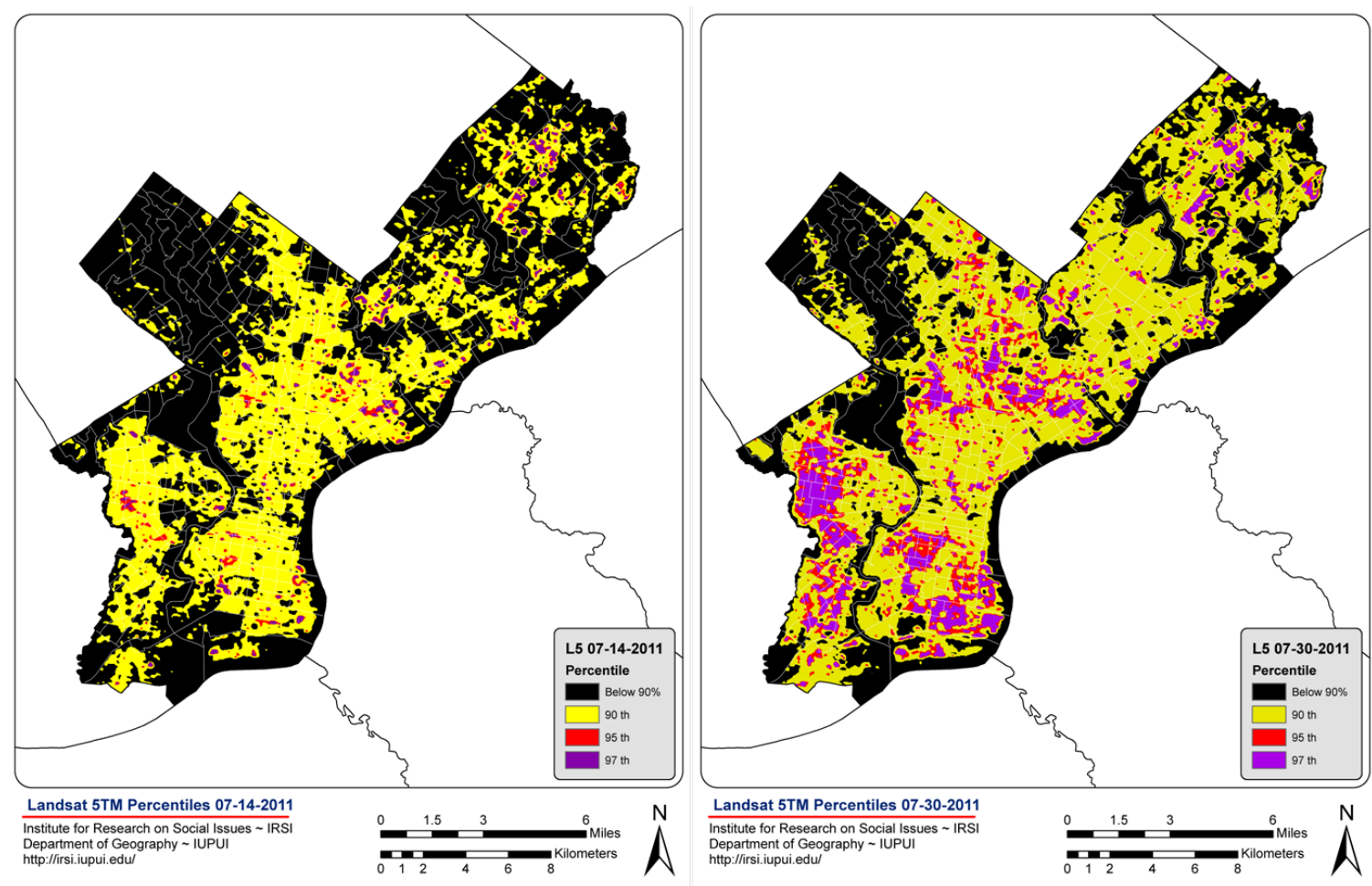
Figure 2. Chicago EHVI 1990, 2000, and 2010 Map
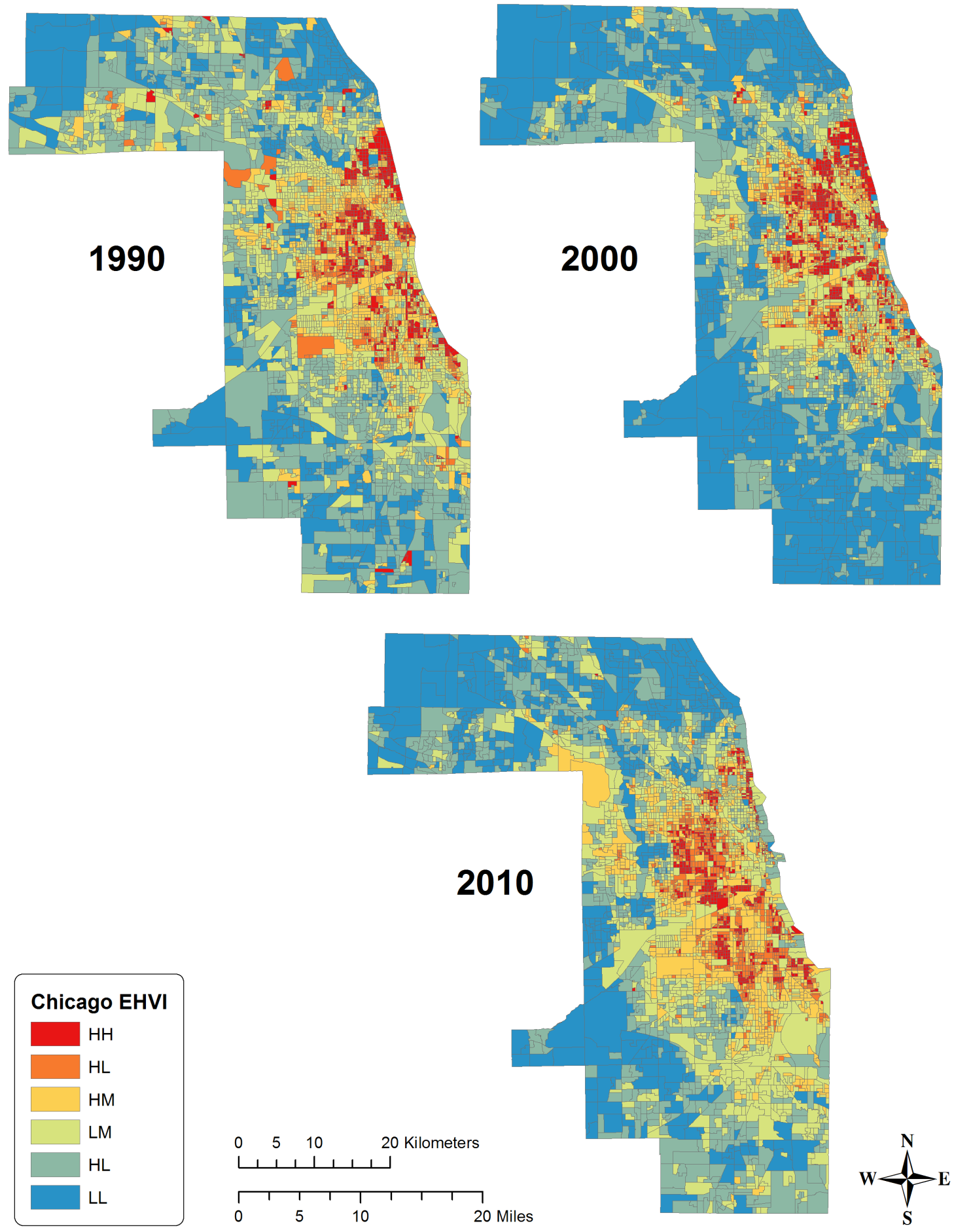
Figure 3. Indianapolis EHVI 1990, 2000, and 2010 Map

\section{0}

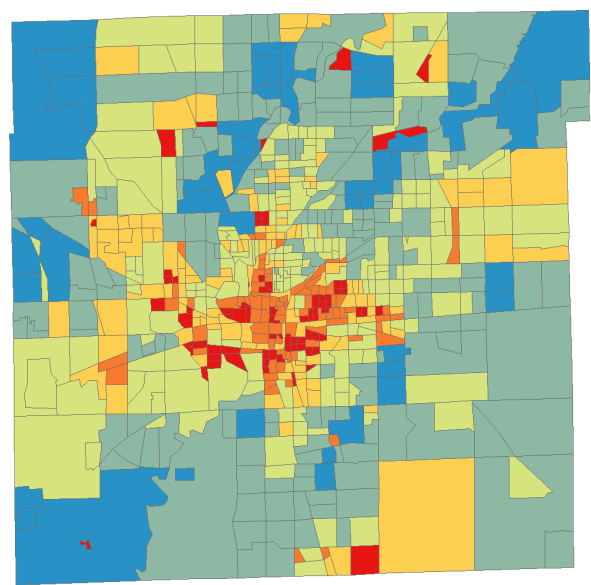

2000

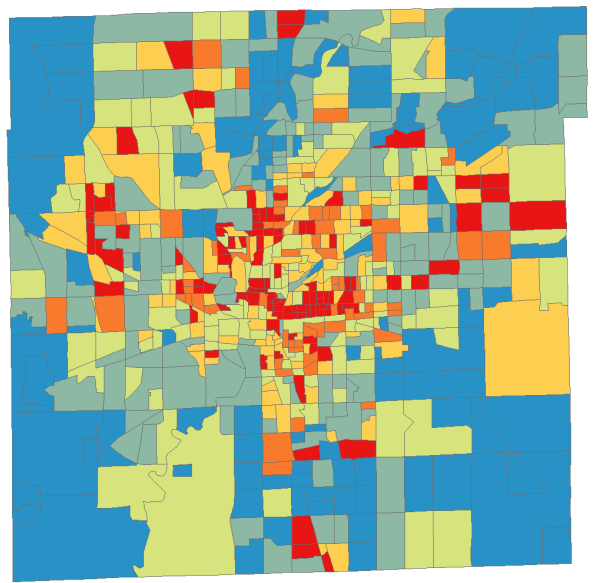

\section{0}

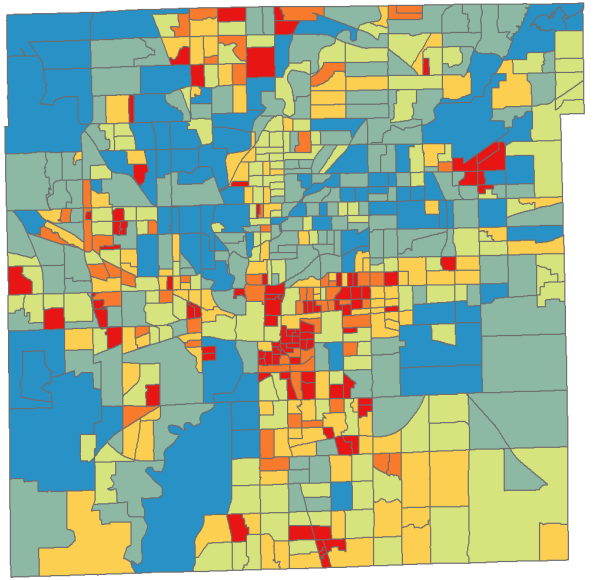

Indianapolis EHVI

\begin{tabular}{|l|l|}
\hline & $H H$ \\
\hline & $H L$ \\
\hline & $H M$ \\
\hline & $\mathrm{LM}$ \\
\hline & $\mathrm{HL}$ \\
\hline $\mathrm{LL}$ & \\
\hline
\end{tabular}

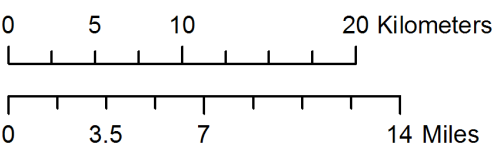

$\overbrace{S}^{N}$ 
Figure 4. Dayton EHVI 1990, 2000, and 2010 Map
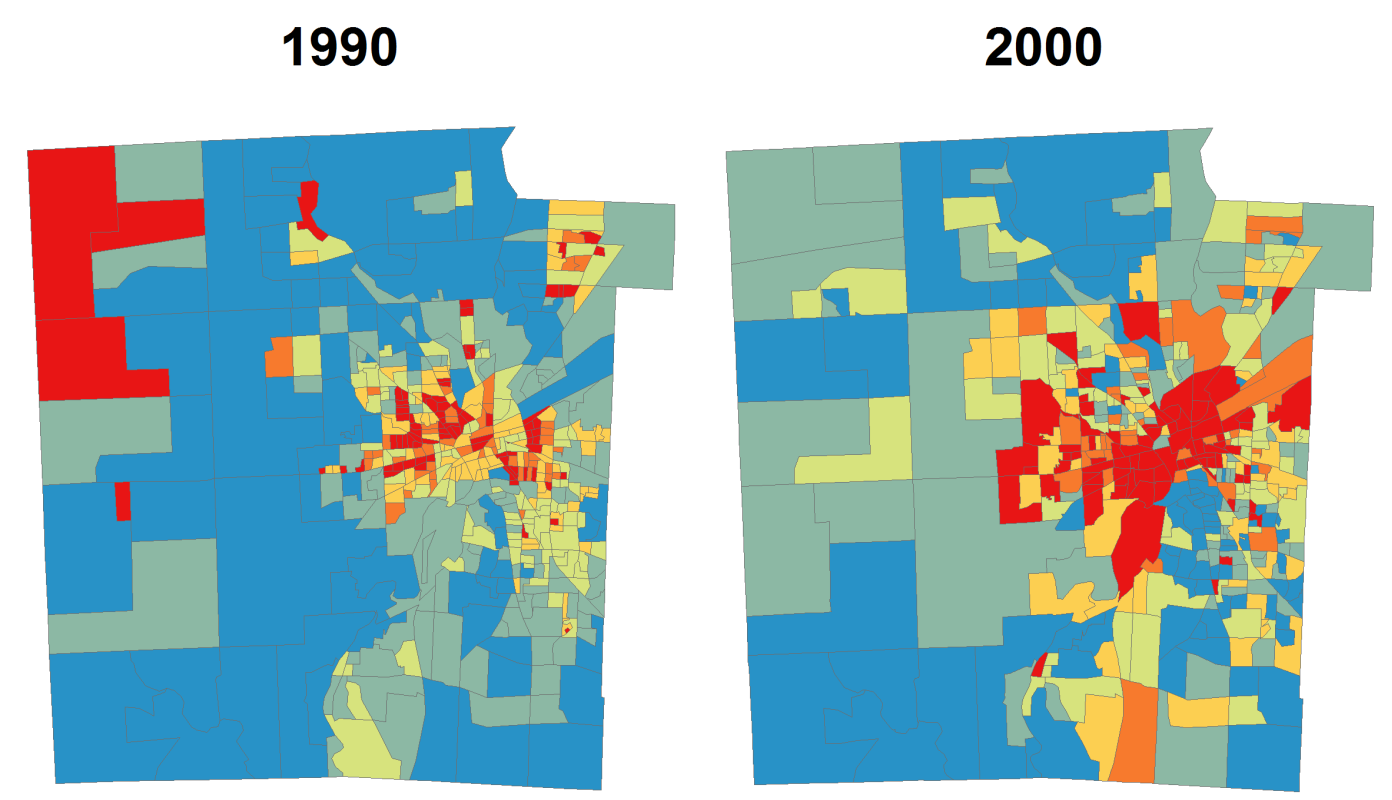

\section{0}

\begin{tabular}{|c|}
\hline Dayton EHVI \\
HH \\
HL \\
HM \\
LM \\
HL \\
LL \\
\hline
\end{tabular}
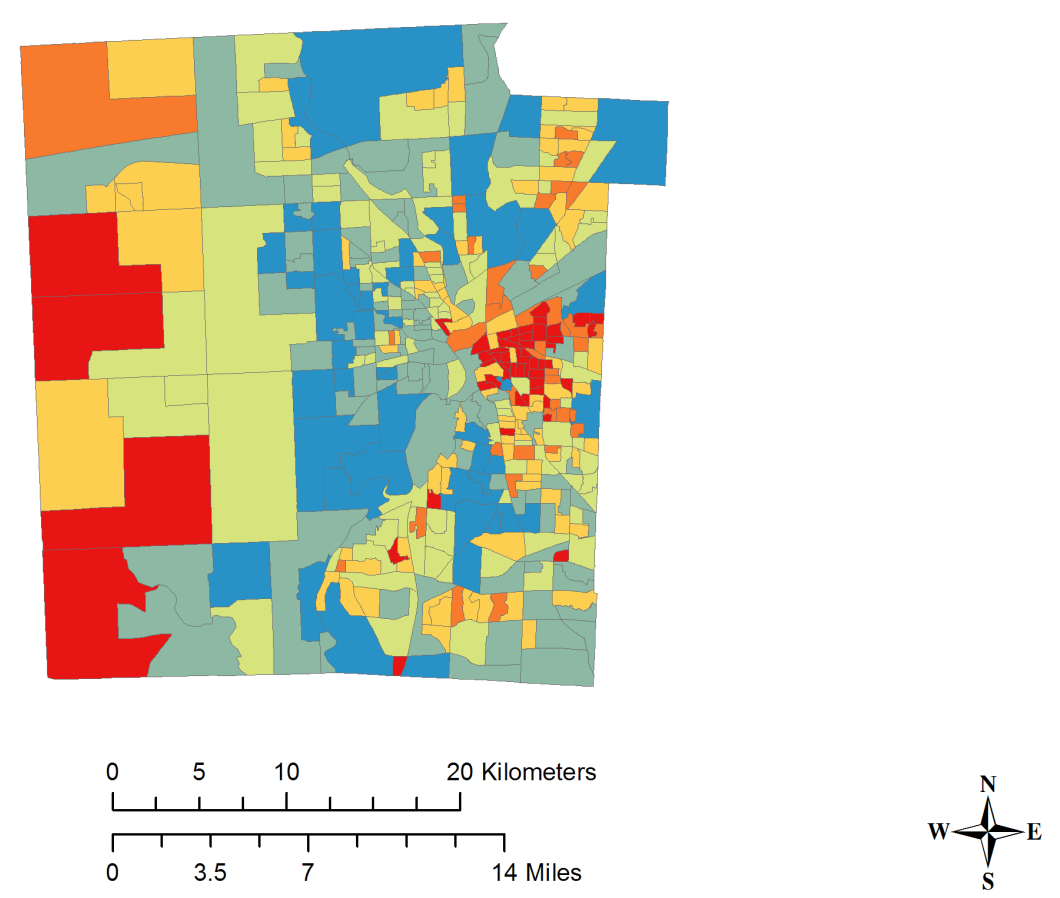